\title{
Modeling of a Buss-Kneader as a Polymerization Reactor for Acrylates. Part II: Methyl Methacrylate Based Resins
}

\author{
E. J. TROELSTRA, L. L. VAN DIERENDONCK, and L. P. B. M. JANSSEN* \\ Department of Chemical Engineering \\ University of Groningen \\ Nijenborgh 4, 9747 AG Groningen, The Netherlands
}

A. RENKEN

Swiss Federal Institute of Technology
CH-1015 Lausanne, Switzerland

\begin{abstract}
The Buss-Kneader has proven to be a suitable reactor for the polymerization of acrylates. In this second part, the polymerization of methyl methacrylate and the ter-polymerization of methyl methacrylate (MMA), hydroxyethyl methacrylate and n-butylmethacrylate is carried out in a pilot Buss-Kneader. The reactor had to be pressurized up to about 10 bars to avoid evaporation of MMA. Instabilities in output rate and temperature profiles were observed as a result of fluctuating die pressures. Because of good mixing there may be no diffusion limitation for radicals. As a result, even at high conversions, no gel effect was observed.
\end{abstract}

\section{INTRODUCTION}

$\mathrm{P}$ art I of this paper proved that the Buss-Kneader is a suitable polymerization reactor for several acrylates for the production of acrylic resins. Methyl methacrylate (MMA) is one of the main components of acrylic resins used in the coating industry. The polymerization of MMA has been carried out successfully in twin-screw extruders $(1,2)$. Until now, no study of the polymerization of MMA in a Buss-Kneader has been published.

The polymerization of methyl methacrylate differs in three ways from the co-polymerization of nBA and HEMA:

- DSC experiments with MMA (3) show the occurrence of a gel effect (4) by a strong increase of the polymerization at conversions above $50 \%$.

- The produced polymer is highly viscous (1). This can result in considerable viscous dissipation of energy during a reactive extrusion process.

- Owing to the high vapor pressure of MMA, a pressure of several bars within the extruder is required to avoid evaporation at the reaction

\footnotetext{
To whom correspondence should be addressed. E-mail: L.P.B.M.Janssen@ chem.rug.nl

This paper was extracted from the Ph.D. thesis of E.J. Troelstra published in
} 1998, Untversity of Groningen. The Netherlands. temperature between $100^{\circ} \mathrm{C}$ and $160^{\circ} \mathrm{C}$. At these temperatures, the vapor pressure is in the range of 1 to 4 bar.

To study these aspects, the homo-polymerization of MMA is carried out within a pilot Buss-Kneader. Finally, ter-polymer acrylic resins, based on MMA, nbutylacrylate (nBA) and hydroxyethyl methacrylate (HEMA) are prepared. Such ter-polymers are applied in coating industry.

\section{REACTOR MODEL}

In part I of this paper, the axial dispersion model was applied successfully to describe the co-polymerization of nBA and HEMA. Axial temperature profiles, conversion and molecular weights could be calculated, although the polymerization kinetics had to be adjusted compared to the kinetics measured by DSC. A decreased polymerization rate had to be used in the reactor model.

The reactor model developed (part I) is used to discuss the experimental results on the homo-polymerization of methyl methacrylate and the production of the ter-polymer acrylic resin.

\section{EXPERIMENTAL SETUP}

The polymerization reactions are carried out in a pilot Buss-Kneader PR $46(D=46 \mathrm{~mm}, L / D=15, V=0.51)$ 
equipped with kneading elements over its entire length. For ter-polymerization, the different monomer types are premixed. Peroxide and monomers are dosed separately through an inline static mixer. The static mixer provides a micro-mixed feed of monomers and peroxide. The flow rate is varied between 1 and $6.6 \mathrm{l} / \mathrm{h}$ and the screw rotation speed between 60 and $285 \mathrm{rpm}$. Temperature settings of screw and barrel were $125^{\circ} \mathrm{C}$ in all cases. Different dies were used to discharge the product. Contrary to the experiments described in part $I$, the kneader was completely filled during all experiments. In the experiments with MMA, a fully filled kneader was ensured by increasing the flow rate at a constant screw speed until a pressure at the inlet of 5-10 bars was reached. This pressure is above the vapor pressure of MMA at the reaction temperature of $\max .150^{\circ} \mathrm{C}$. In the ter-polymerization of MMA, HEMA, and nBA, it was possible to adjust the die resistance to obtain an inlet pressure of 5-10 bars to ensure a fully filled kneader.

The monomer contents of the output are analyzed by gas chromatography. The molecular weight is measured with a GPC apparatus equipped with two mixed C $5 \mu \mathrm{m}$ columns in series calibrated with pMMA narrow standards.

\section{HOMO-POLYMISRIZATION OF METHYL METHACRTLATE}

The free radical addition homo-polymerization of MMA (BASF) was carried out in the pilot BussKneader. The reaction was initiated by the peroxide tert-butyl peroxy-2-ethylhexanoate. A $50 \%$ solution of this peroxide in iso-dodecane, was used (Luperox 26R-M-50, Elf Atochem). The initiator flow rate was adjusted to obtain a $0.5 \mathrm{~mol} \%$ concentration of active peroxide within the reaction mixture.

\section{Polymerization Kinetics}

The kinetic scheme for a radical addition polymerization is given in Table 1. Fleury (3) studied the polymerization kinetics of the bulk-polymerization of MMA by differential scanning calorimetry (DSC). These DSC experiments show an increase of the polymerization rate at conversions above $50 \%$. This phenomenon is known as the gel effect or Trommsdorff effect (4). At these high conversions, there is a strong increase of the viscosity. As a consequence, the diffusion of the polymer radicals decreases and therefore the termination rate decreases. Fleury (3) described the observed gel effect for the polymerization of MMA based on an empirical diffusion model developed by Chiu et al. (5). In this model the termination rate constant $k_{t}\left(=k_{t, c}+k_{t, d}\right)$ reads:

$$
k_{t}=k_{t, 0} \cdot \frac{1}{1+\frac{\gamma \cdot k_{t, 0}}{e^{(\alpha-\beta \cdot X)}}}
$$

with:

$$
\alpha=\alpha_{0}+\operatorname{Ln}\left(c_{I 0} / c_{R, \min }\right)^{0.56}
$$

Table 1. Kinetic Scheme for the Free Radical Addition Polymerization.

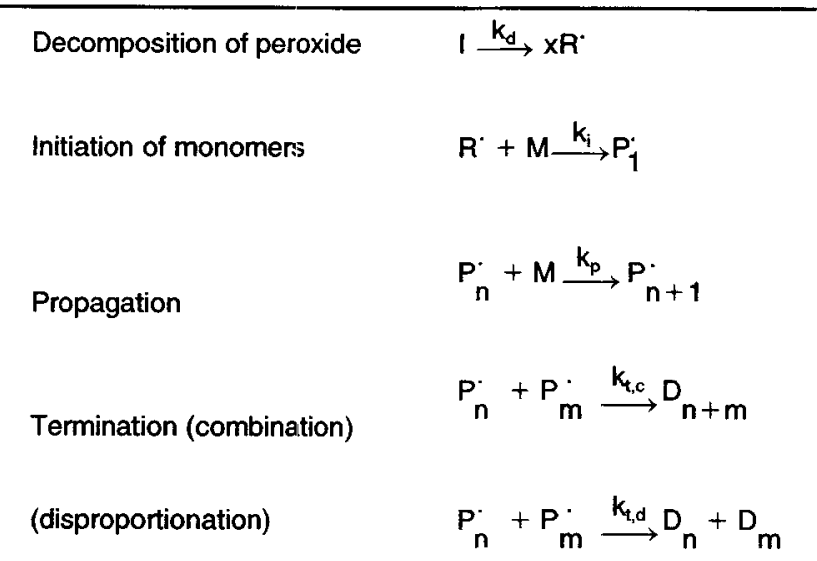

where $k_{x}$ are the correspionding rate constants and depend on temperature according to the Arrhenius correlation:

$$
k=A_{0} \cdot e^{-\frac{E_{A}}{R \cdot T}}
$$

$P_{n}$ denotes a growing ccpolymer (radical) of $n$ monomer units. $D_{n}$ denotes a dead copolymer of $\mathbf{n}$ monomer units. $x$ stands for the number of radicals produced from decomposition of 1 peroxide molecule.

$$
\begin{gathered}
\beta=\beta_{0}+\frac{T-T_{g P}}{T_{r e f}-T_{g P}}+2.32 \cdot\left[1-e^{-\left(\frac{{ }_{0} / c_{\text {momn }}}{3.34}\right)}\right] \\
\gamma=1
\end{gathered}
$$

This empirical model will also be used in this paper to describe the possible occurrence of the gel effect during the polymerization of MMA. All kinetic constants, except the peroxide efficiency, are obtained from literature and presented in Table 2 . The exact value of the peroxide efficiency is not known. The kinetic constants are based on measurements using benzoyl peroxide as initiator, assuming a peroxide efficiency of 1 (6). However, according to the literature, the peroxide efficiency is decreasing at increasing conversions (7). Besides that, the kinetics depend on the type of peroxide used.

\section{Pressure Control and Process Stability}

For twin-screw extrusion, high die-pressures can be applied to maintain the vapor pressure. Stuber et al. (1) reported die pressures of about 100 bars, and pressure gradients are relatively steep. In a BussKneader, steep pressure gradients cannot be obtained as a result of the interrupted flights, especially when kneading elements are used (8). Kneading elements were used during the experiments for their good selfcleaning properties. If a pressure gradient exists, negative or positive, the Kneader is completely filled. In this case the die pressure has a relatively large influence on the degree of fill (Fig. 1). Therefore the Kneader will empty itself rapidly when the die pressure drops 
E. J. Troelstra, L. L. Van Dierendonck, L. P. B. M. Janssen, and A. Renken

Table 2. Kinetic Parameters Polymerization of MMA.

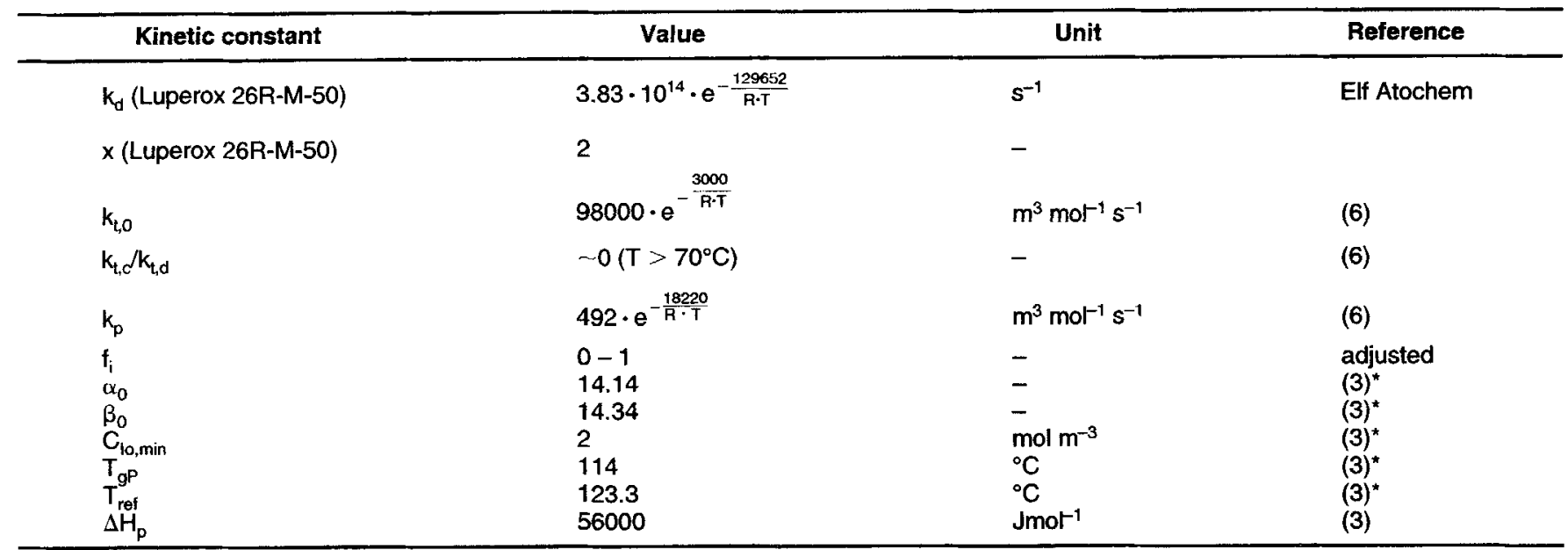

*Validated for $135<T<165^{\circ} \mathrm{C}$ and $2<C_{10}<200 \mathrm{~mol} / \mathrm{m}^{3}$

slightly. This mechanism can give rise to instabilities during reactive extrusion (9). The die pressure strongly depends on viscosity. In reactive extrusion, the viscosity depends exponentially on conversion. The coupling of both phenomena induces large changes in die pressures and therefore in the degree of fill. Van der Goot reported such instabilities during the co-polymerization of styrene and butyl methacrylate in a counterrotating twin-screw extruder $(10,11)$. Jongbloed reported instabilities for the co-polymerization of butyl methacrylate and hydroxyethyl methacrylate (12).

Comparable instabilities were obtained when a die plate was used during the polymerization of MMA within a pilot Buss-Kneader. The discharge opening of the die has a diameter of $15 \mathrm{~mm}$ and an axial length of about $2 \mathrm{~mm}$. The die pressure was adjusted by covering the die opening partly. Instabilities arose at throughputs above $3 \mathrm{l} / \mathrm{h}$ and appeared as fluctuations in output rate, in- and outlet pressure and in temperatures of the reaction mixture measured at several axial positions. Because of the short axial length of the dieplate, a local change of the viscosity results in an immediate change of the die pressure. In order to prevent these instabilities, the experimental setup was modified. A heated die tube with an internal diameter of 15 $\mathrm{mm}$ and an axial length of $10 \mathrm{~cm}$ was used this time. Local changes in viscosity within the die tube are averaged and the die pressure is less dependent on viscosity changes. A stable process could be obtained in this case up to flow rates of $6.6 \mathrm{l} / \mathrm{h}$.

Using a gear pump as discharge unit will make the output rate independent of the viscosity of the extruded material, resulting in stable processing. This, however, has not been studied during this work.
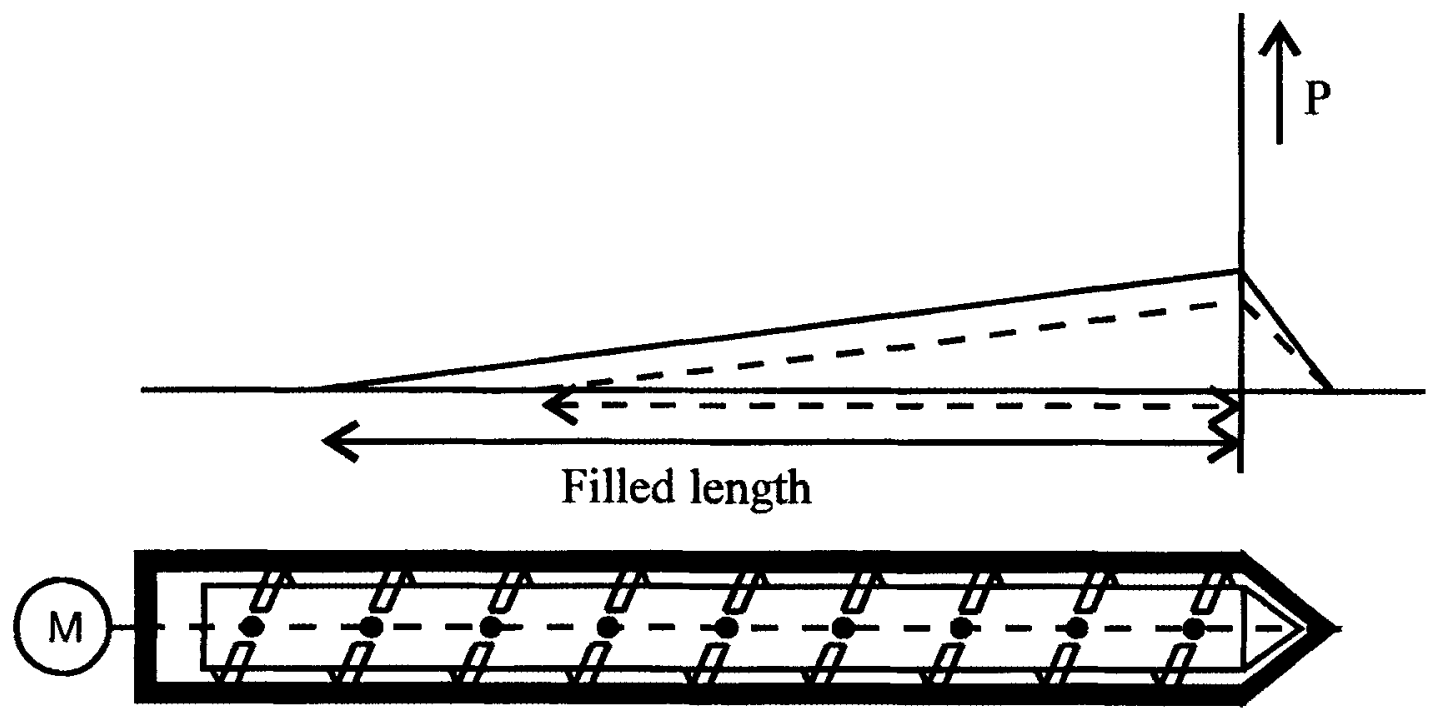

Fig. 1. Influence of die pressure on degree of fill within an extruder or Buss-Kneader. A small change of the die pressure results in a large change of the degree of fill. 


\section{Results}

The measured mass output rate was generally slightly lower than the volumetrically measured input rate, especially at low conversions of the product. This is due to evaporation of MMA at the die. Conversions were calculated as the product of the ratio of the input rate over the output rate and the polymer content of the sample:

$$
X=\frac{\text { mass input rate }}{\text { mass output rate }} \cdot(1-M)
$$

where $M$ is the monomer content within the sample.

Similar to the findings in part $I$, calculations based on the polymerization kinetics including the gel effect appear to deviate strongly from experimental results. The dotted curves in Fig. 2 and Fig. 3 show that both the temperature increase and the conversion as calculated are much larger than those obtained by experiments. However, when calculations are performed neglecting the gel effect, much better agreement between model and experiment is obtained (solid curves, Figs. 3 and 4). This leads to the contention that possibly no gel effect occurs when this radical polymerization is carried out in high-intensity mixing devices. The gel effect is related to a decrease of the mobility of the growing chains. This results in a decreasing termination velocity, leading to an increased reaction velocity and an increased molecular weight. Over the last decade, some studies were performed to understand the occurrence of the gel effect quantitatively (13). Shear stress within extruders might increase the mobility of the polymer chains as a result of molecular orientation and destruction of entanglements. As discussed previously, the peroxide efficiency is not known exactly. Decreasing the peroxide efficiency results in further improved correspondence between calculated and measured conversions (Fig. 3).

Higher temperatures were obtained at increasing screw speeds as a result of viscous dissipation.

In all cases the obtained polymer had a number average molecular weight of about $20 \mathrm{~kg} / \mathrm{mole}$ and a weight average molecular weight of about $120 \mathrm{~kg} /$ mole.

\section{PREPARATION OF AN ACRTLIC RESIN FOR COATING PURPOSES}

Ter-polymers of MMA, nBA and HEMA (BASF) were produced at three fixed compositions: MMA:nBA: HEMA $=70: 15: 15$ wt $\%$, MMA:nBA:HEMA $=35: 30: 35$ wt\% and MMA:nBA:HEMA = 45:20:35 wt\%. When acrylic resins are prepared for powder-coating purposes, the molecular weight of the polymer has to be relatively low and therefore a high peroxide concentration is required. The flow rate of the peroxide was adjusted to obtain a peroxide concentration in the reaction mixture of $2.4 \mathrm{wt} \%$ tert-amyl peroxy-2ethylhexanoate (Luperox 575, Elf Atochem). In addition $0.6 \mathrm{wt} \%$ of the relatively slow decomposing tert-butyl

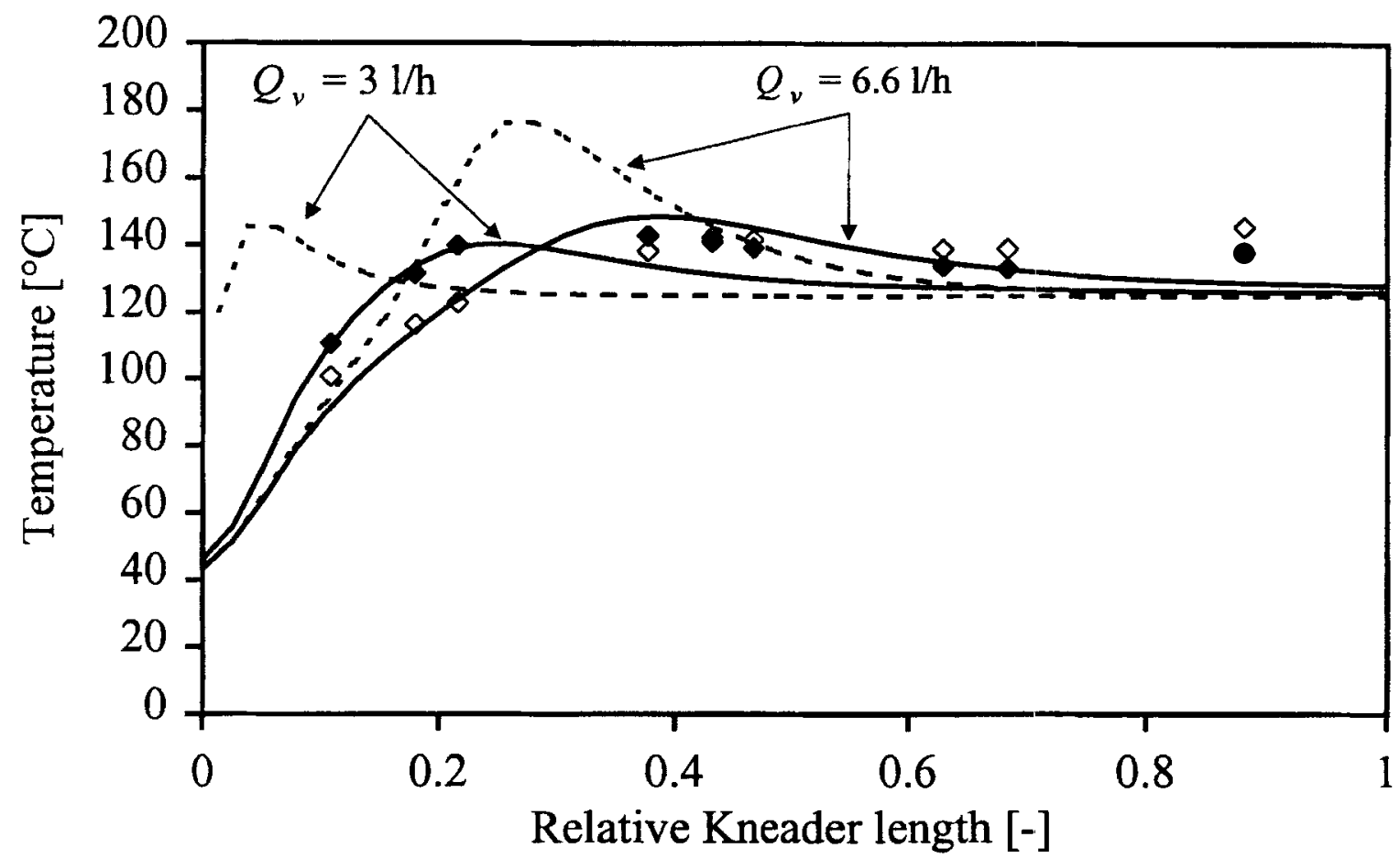

Fig. 2. Polymerization of MMA within Buss-Kneader. Measured and calculated axial temperature profiles. Temperature settings of screw and barrel: $125^{\circ} \mathrm{C}$.peraxide efficiency $f_{i}=1 . Q_{v}=3 l / h, N=100 \mathrm{rpm}(\bullet) ; Q_{v}=6.6 \mathrm{l} / \mathrm{h}, N=220$ rpm $(\diamond) ;$ Calculated, gel effect neglected (-); Calculated, including gel effect $(--)$. 
E. J. Troelstra, L. L. Van Dierendonck, L. P. B. M. Janssen, and A. Renken

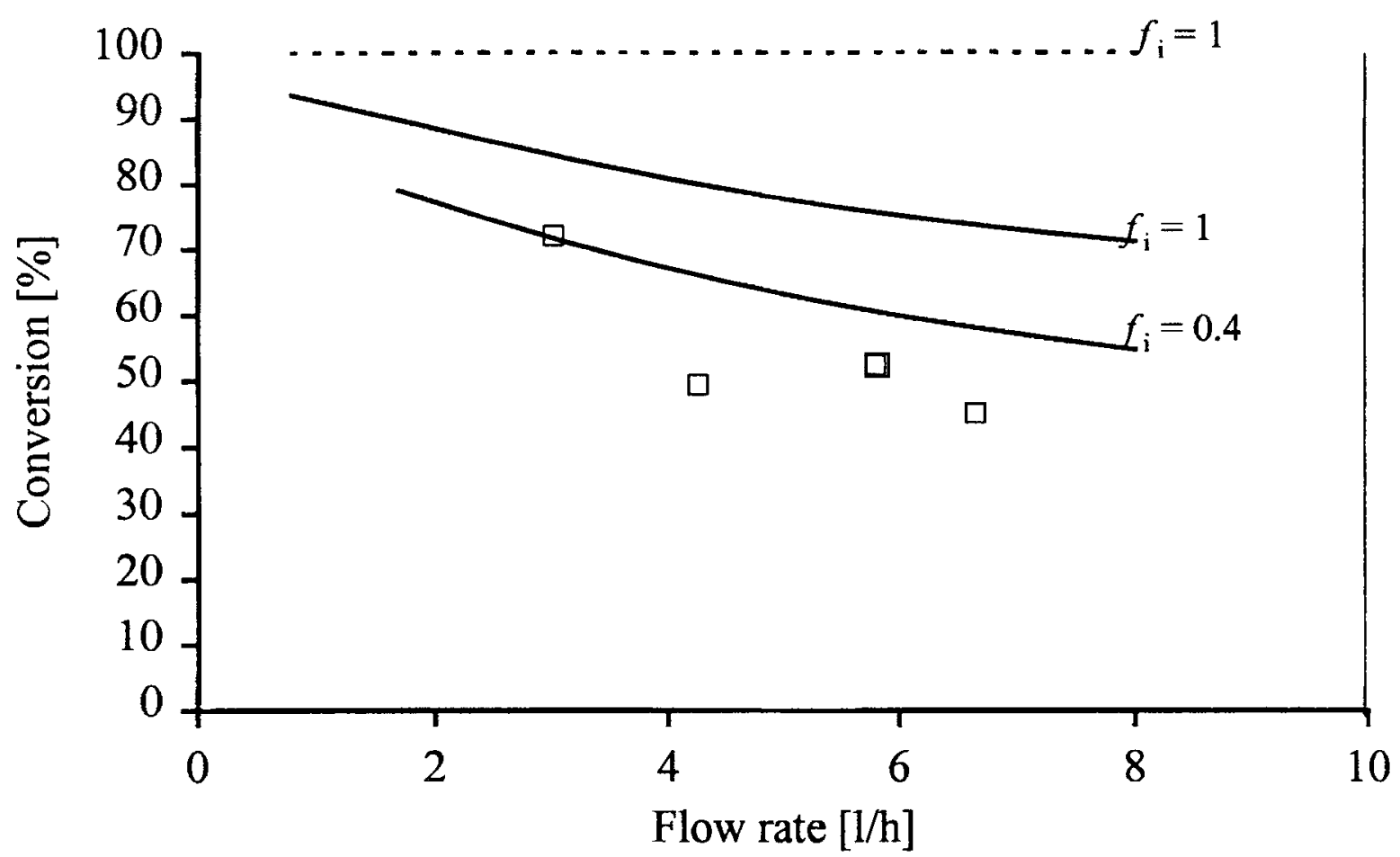

Fig. 3. Polymerization of MMA within Buss-Kneader. Calculated and measured conversions as a function of flow rate. Temperature

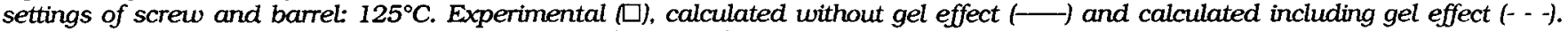
Screw rotation speed is increased proportionally to flow rate from $100 \mathrm{rpm}$ to $220 \mathrm{rpm}$.

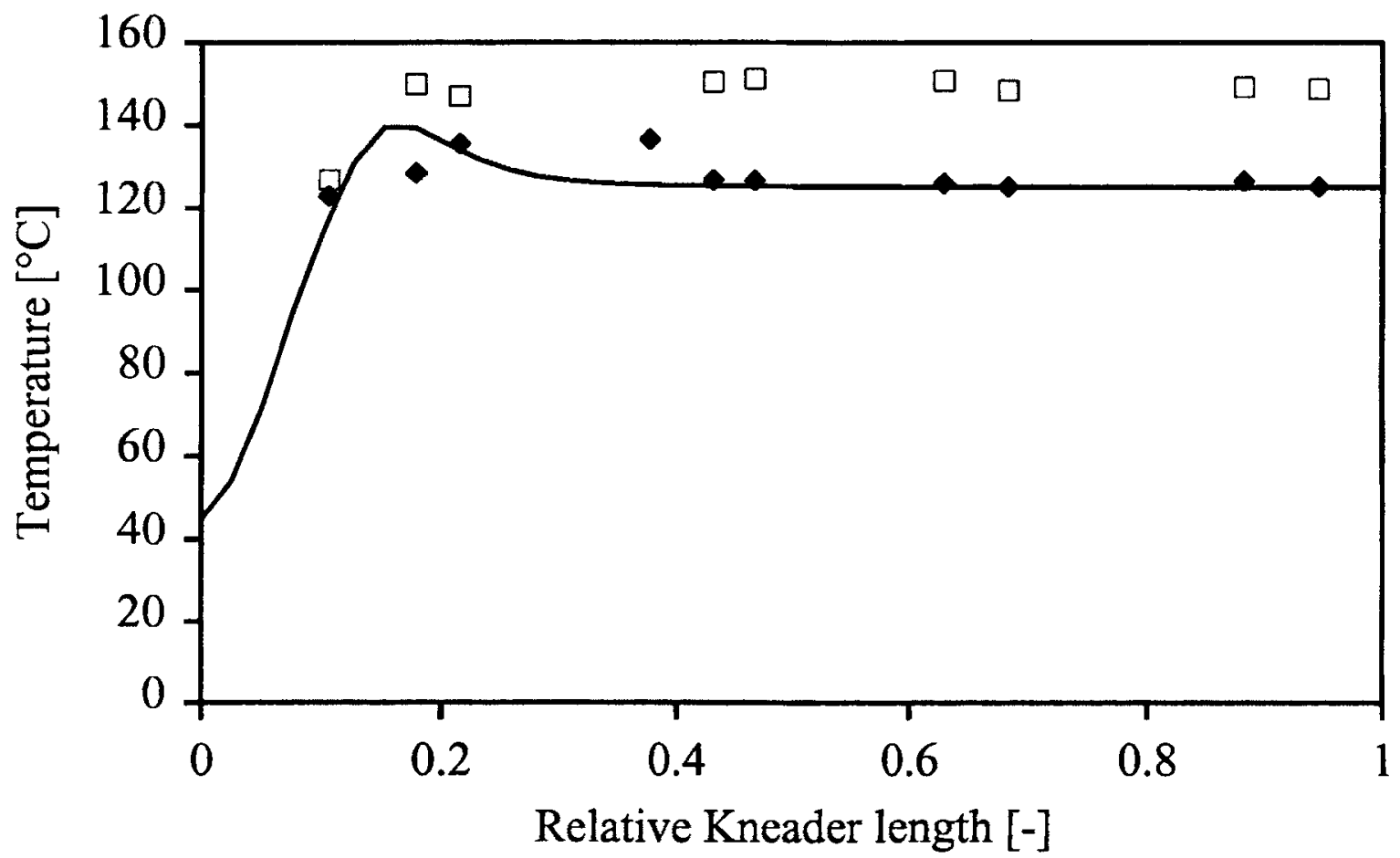

Fig. 4. Measured and calculated axial temperature profiles. Temperature settings of screw and barrel: $125^{\circ} \mathrm{C}$. Flow rate is $1.8 \mathrm{l} / \mathrm{h}$. Experimental MMA:nBA:HEMA $=70: 15: 15 \mathrm{wt} \% . N=60 \mathrm{rpm}(\bullet)$ and $N=285 \mathrm{rpm}(\square)$. Calculated without gel effect, $f_{t}=1$, MMA: $\mathrm{BAA}:$ HEMA $=66: 15: 19 \mathrm{wt} \%(\longrightarrow)$. 
peroxy-2-ethylhexanoate (Luperox 26R-M-50, Elf Atochem) was added to ensure peroxide activity at high temperatures. Performed calculations are based on 3 wt $\%$ tert-amyl peroxy-2-ethylhexanoate.

\section{Polymerization Kinetics}

The polymerization kinetics of the ter-polymerization of MMA, nBA and HEMA have been studied by Maeder (14). The initial monomer ratio of MMA:nBA:HEMA = 66:15:19 wt\% used by Maeder is comparable with the ratio of $70: 15: 15$ wt\% used in this work. An overall polymerization rate constant defined similar to the rate constant for the homo-polymerization of MMA has been measured. The kinetic constants as measured by Maeder (13) by means of DSC are summarized in Table 3. Maeder observed in his experiments a gel effect and described the termination rate constant with $E q 1$.

\section{Pressure Control and Process Stability}

Because of the low viscosity of the polymer, a die diameter smaller than the one used for the homo-polymerization of MMA was necessary to maintain the pressure within the Kneader. An adjustable die with a maximum diameter of $0.5 \mathrm{~cm}$ was used. The pressure could be measured at the inlet, halfway and within the die of the Kneader. To avoid evaporation of MMA, a pressure between 7 and 10 bars was maintained throughout the reactor by adjusting the die resistance. Pressures measured halfway in the Kneader and at the inlet were of the same order of magnitude. Pressures measured within the die were about 3 bars. Apparently, the pressure is already reduced at the entrance of the die. Stable processing required a continuous adjustment of the die resistance to keep pressures constant.

\section{Results}

Axial temperature profiles and conversions are calculated using the polymerization kinetics as given in Table 3. Again, good agreement is obtained between calculated and experimentally (MMA:HEMA:nBA =
70:15:15) obtained temperature profiles and conversions if the occurrence of a gel effect is neglected.

At increasing screw speeds ( $N=285 \mathrm{rpm})$, viscous dissipation becomes significant and calculations deviate from measured values $(F i g$. 4). Viscous dissipation is not included in the model. Figure 5 shows that the overall conversion decreases when the amount of MMA decreases. This is in agreement with the kinetic work of Maeder (13), who concluded that the addition of $\mathrm{nBA}$ in this ter-polymerization results in a decrease of the overall polymerization rate.

The molecular weight as measured by means of GPC, calibrated with MMA standards was in the following range: $\vec{M}_{n}=3-5 \mathrm{~kg} /$ mole: $\vec{M}_{w}=20-$ $35 \mathrm{~kg} /$ mole. $\bar{M}_{n}$ and $\bar{M}_{w}$ decreased with increasing throughput.

\section{Insoluble Products}

The ter-polymers produced contain insoluble products, especially those with a high HEMA content. Therefore no application tests were performed with the samples produced. The formation of insoluble products with polymerization reactions involving HEMA is not unknown. The insoluble products are probably crosslinked fractions. This crosslinking was observed during the experiments described in this work, where tert-butyl peroxy-2-ethylhexanoate (Luperox 26R) was used as peroxide, as well as by Maeder (13), who used benzoyl peroxide as initiator. The radicals produced by these peroxides have a large bond dissociation energy and are thus capable of inducing crosslinking by hydrogen abstraction.

\section{CONCLUSIONS}

In correspondence with the results described in part 1 of this paper, the polymerization rate observed during reactive extrusion is lower than the polymerization rate measured in a DSC apparatus. There is a strong indication that the gel effect does not occur in a mixing device like an extruder. It is proposed that molecular diffusion limitation of the termination reaction is eliminated, even at high conversions, as a result of strong micro mixing.

Table 3. Kinetic Parameters Ter-Polymerization of MMA:HEMA:BA=66:19:15 wt\%.

\begin{tabular}{|c|c|c|c|}
\hline Kinetic constant & Value & Unit & Reference \\
\hline \multirow[t]{2}{*}{$k_{d}($ Luperox 26R-M-50) } & $3.83 \cdot 10^{14} \cdot e^{-\frac{129652}{R \cdot T}}$ & $s^{-1}$ & Elf Atochem \\
\hline & $\underline{145000}$ & & \\
\hline$k_{d}$ (Luperox 575) & $1.07 \cdot 10^{17} \cdot e^{-\overline{R \cdot T}}$ & $s^{-1}$ & Elf Atochem \\
\hline$X$ (Luperox 26R-M-50 and 575) & 2 & - & \\
\hline $\mathbf{k}_{\mathrm{t}, 0}$ & $98000 \cdot e^{-\frac{3000}{R \cdot T}}$ & $\mathrm{~m}^{3} \mathrm{~mol}^{-1} \mathrm{~s}^{-1}$ & $\operatorname{MMA}(6)$ \\
\hline$k_{t, c} / k_{t, d}$ & $\sim 0\left(\mathrm{~T}>70^{\circ} \mathrm{C}\right)$ & - & (6) \\
\hline$k_{p}$ & $6.0 \cdot 10^{5} \cdot e^{-\frac{42200}{R \cdot T}}$ & $\mathrm{~m}^{3} \mathrm{~mol}^{-1} \mathrm{~s}^{-1}$ & (14) \\
\hline$\stackrel{f_{i}}{\Delta H_{p}}$ & $\begin{array}{l}1 \\
60000\end{array}$ & $\bar{J} \mathrm{~mol}^{-1}$ & (14) \\
\hline
\end{tabular}




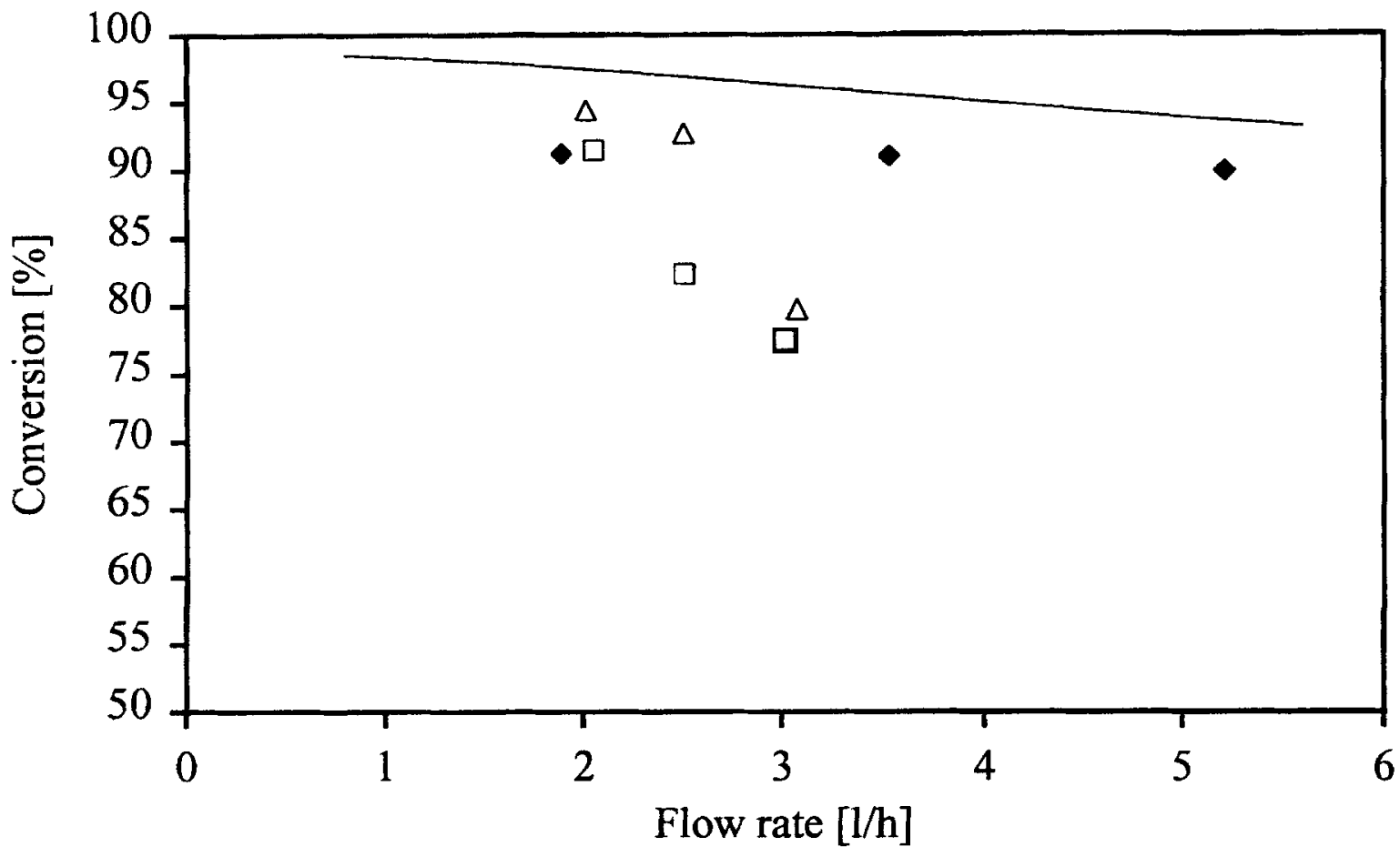

Fig. 5. Measured and calculated conversions as a function of flow rate. Temperature settings of screw and barrel: $125^{\circ} \mathrm{C}$. Experimental MMA:nBA:HEMA = 70:15:15 wt\%. $N=60-285 \mathrm{rpm}\left(\sim \mathcal{B}_{y}\right)(\bullet):$ MMA:nBA:HEMA $=35: 30: 35 w t \% ., \mathrm{N}=60 \mathrm{rpm}(\square)$; MMA:TBA:HEMA = 45:20:35 wt\%., $N=60$ rpm ( $\rho$ ). Calculated without gel effect, $f_{i}=1$. MMA:nBA:HEMA = 66:15:19 wt\% (-).

The dependency of the die pressure on the degree of fill within an extruder or the Buss-Kneader gives rise to instabilities during reactive extrusion. It is expected that the stability of a reactive extrusion process is improved when a gear pump is used as a discharge device.

The ter-polymer produced from HEMA, MMA, and nBA contained insoluble fractions. Radicals produced by the peroxide used were capable of inducing crosslinking by hydrogen abstraction.

\section{ACKNOWLEDGMENTS}

The assistance of the students Peter Stuut (MMA polymerization), Margot Kerkvliet (MMA Polymerization) and Maarten van der Zwaag (ter-polymerization) is gratefully acknowledged. This study is financially supported by Buss Compounding Systems AG, Pratteln (Switzerland), DSM-Research, Geleen (The Netherlands), CERS, Bern (Switzerland) and 'AIO-Netwerk' (The Netherlands).

\section{NOMENCLATURE}

MMA methyl methacrylate

HEMA hydroxyethyl methacrylate

n-BA n-butylacrylate

Luperox

26R-M-50

commercial name for tert-butyl peroxy2-ethylhexanoate as a $50 \mathrm{w} \%$ solution in iso-dodecane (Elf Atochem)
Luperox 575 commercial name for tert-amyl peroxy-2-ethylhexanoate (Elf Atochem)

I peroxide molecule

$R^{\prime} \quad$ radical from decomposed peroxide

M monomer molecule

$A_{0}$ pre-exponential factor

$C_{\digamma O}$ initial initiator concentration $\quad \mathrm{mol} \mathrm{m}^{-3}$

$\mathrm{C}_{I 0, \min }$ model parameter $\mathrm{mol} \mathrm{m}^{-3}$

$D_{n}$ number of dead polymer chains of length $n$

$D$ Diameter $\mathbf{m}, \mathbf{m m}$

$E$ effective heat axial dispersion coefficient $\mathrm{m}^{2} \mathrm{~s}^{-1}$

$E_{\mathrm{A}}$ activation energy

$f_{i}$ peroxide efficiency

$k_{d}$ rate constant for peroxide decomposition

$k_{p}$ rate constant for propagation

$$
\mathrm{m}^{3} \mathrm{~mol}^{-1} \mathrm{~s}^{-1}
$$

$k_{t 0}, k_{t}$ rate constant for termination, index 0 in case of initial value $\quad \mathrm{m}^{3} \mathrm{~mol}^{-1} \mathrm{~s}^{-1}$

$k_{t, c}, k_{t, d} \quad$ rate constant for termination by combination and termination by disproportionation. $\quad \mathrm{m}^{3} \mathrm{~mol}^{-1} \mathrm{~s}^{-1}$

$L$ length of the reactor $m$

$\overline{M_{n}}$ number average molecular weight

$\overline{M_{w}} \quad$ weight average molecular weight

M Monomer content $\mathrm{kg} \mathrm{mol}^{-1}$ kg mol-1 


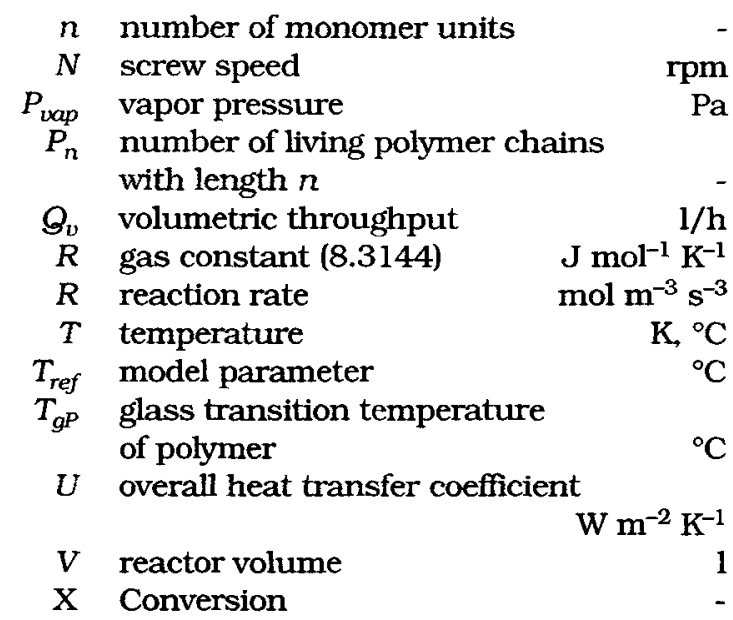

$\alpha, \alpha_{0}, \beta, \beta_{0}, \gamma$

Model parameters to describe $k_{t}$ according to Chiu et al. (5)

$\Delta H_{p} \quad$ polymerization enthalpy $\quad \mathrm{J} \mathrm{mol}^{-1}$

\section{REFERENCES}

1. J. A. Stuber and M. Tirrell, Polm. Proc. Eng., 3, 71 (1985).

2. J. P. Puaux, A. Ainser, and A Stefan, DECHEMA Monographs, 5th International Workshop on Polym Reaction Eng., 131, 171 (1995).
3. P. A. Fleury, Thesis Nr. 1177, EPF Lausanne, Switzerland (1993).

4. E. Trommsdorff, H. Köhle, and P. Lagally, Makromol. Chem, 1, 169 (19.48).

5. W. Y. Chiu, G. M. Carret, and D. S. Soong, Macromolecules, 16, 348 (1983).

6. M. B. Louie, G. M. Carat, and D. S. Soong, J. Appl. Polym. Sci., 30, 3985 (1985).

7. N. Tefera, G. Weickert, and K. R. Westerterp, J. of Appl. Polym. Sci. 63. 1649 (1997).

8. P. Elemans, Modtelling of the Processing of Incompatible Polymer Blends, $\mathrm{PhD}$ thesis, Technical University Eindhoven, The Netherlands (1989).

9. L. P. B. M. Janssen, Polm. Eng. Sci, 38, 2010 (1998).

10. A. J. van der Goot, R. Hettema, and L. P. B. M. Janssen, Polym. Eng. Sci, 3i7, 511 (1997).

11. A. J. van der Goot, S. A. Klaassens, and L. P. B. M. Janssen, Polym. Eng. Sci, 37, 519 (1997).

12. H. A. Jongbloed, J. A. Kiewiet, J. H. van Dijk, and L. P. B. M. Janssen, Polym. Eng. Sci, 35, 1569 (1995).

13. G. A. O'Neil and J. M. Torkelson, Trends in Polymer Sciences, 5, 349 (1997).

14. S. Maeder, Thesis, EPF Lausanne, Switzerland (1996). 